\title{
Jurnal

\section{Analisis Perbandingan Tegangan Statik Material Galvanized Steel Dengan Material Aluminium Alloys 7076-T6 (Sn) Pada Frame Ganesha Scooter Underwater (GSU) Menggunakan Software Solidworks}

\author{
Static Comparison Analysis Of Galvanized Stell Materials With \\ Aluminium Alloys 7076-t5 (SN) Materials On The Frame Ganesha \\ Scooter Underwayet GSU Using Software Solidworks
}

\section{Kholid Firdaus1, Kadek Rihendra Dantes1, I Nyoman Pasek Nugraha1}

1Program Studi Pendidikan Teknik Mesin, Universitas Pendidikan Ganesha, Singaraja, Indonesia

\author{
E-mail : firdaus02@gmail.com, rihendra-dantes@undiksha.ac.id, \\ paseknugraha@undiksha.ac.id
}

\begin{abstract}
Abstrak
Dalam penenlitian ini dilakukan analisis tegangan statik pada rancangan Frame Ganesha Scooter Underwater dengan perbandingan material galvanized steel dan aluminuium alloys 7076T6 menggunakan software Solidworks dengan tanpa beban pengendara dan pembebanan dari pengendara. Tujuan dari penelitian ini adalah untuk mengetahui tegangan statik terbesar pada Frame Ganesha Scooter Underwater menggunakan material galvanized steel dan aluminium alloys 7076-T6 dengan beban $80 \mathrm{Kg}$ dan tanpa beban.

Dari hasil analisis yang telah dilakukan pada frame dengan material galvanized steel dan aluminium alloys 7076-T6 (SN) tanpa beban pengendara maupun dengan beban pengendara mengalami penurunan setelah dilakukan penggantian material aluminium alloys 7076-T6 (SN) yaitu sebesar $8,4 \%$ dan juga tegangan maksimum pada frame dengan material galvanized steel dengan beban pengendara mengalami penurunan setelah dilakukan penggantian material aluminium alloys 7076-T6 (SN) yaitu sebesar 8,4\%.

Kemudian hasil faktor keamanan (factor of safety) pada frame material galvanized steel tanpa beban pengendara mengalami peningkatan setelah dilakukan penggantian material aluminium alloys 7076-T6 (SN) yaitu sebesar 63\%. Dan juga faktor keamanan (factor of safety) pada frame standar material galvanized steel dengan beban pengendara mengalami peningkatan setelah dilakukan penggantian material aluminium alloys 7076-T6 (SN) yaitu sebesar 63,02\%, sehingga dapat dikatakan bahwa pergantian material galvenized steel dengan aluminium alloys 7076-T6 lebih baik dan lebih kuat untuk digunakan.
\end{abstract}

Kata Kunci:Aluminium Alloys, Frame, Galvanized Steel,Tegangan Von Mises

\section{Abstract}

In this research, a static stress analysis was carried out on the Ganesha Scooter Underwater Frame design with a comparison of galvanized steel material and 7076-T6 aluminuum alloys using Solidworks software with no driver load and driver loading. This study aims to determine the greatest static stress in the Underwater Scooter Ganesha Frame using galvanized steel material and 7076-T6 aluminum alloys with a load of $80 \mathrm{~kg}$ and no load From the results of the analysis that has been carried 
out on the frame with galvanized steel material and Aluminum alloys 7076-T6 (SN) without the burden of the driver or the burden of the driver has decreased after the replacement of Aluminum alloys 7076-T6 (SN) material that is equal to $8.4 \%$ and also The maximum stress on the frame with galvanized steel material with the driver's load has decreased after the replacement of Aluminum alloys 7076-T6 (SN) material is equal to 8.4\%. Then the result of the safety factor (factor of safety) on the galvanized steel frame material without the driver's load has increased after the replacement of Aluminum alloys 7076-T6 (SN) material that is equal to 63\%. And also the safety factor (factor of safety) on the standard frame of galvanized steel material with the driver's load has increased after the replacement of Aluminum alloys 7076-T6 (SN) material that is equal to $63.02 \%$, so it can be said that the replacement of galvenized steel material with aluminum alloys 7076-T6 is better and stronger to use.

Keyword: Aluminium Alloys, Frame, Galvanized Steel, Solidworks, Von Mises Teory

\section{PENDAHULUAN}

Ganesha Scooter Underwater merupakan kendaraan jenis scooter air yang dirancang oleh mahasiswa Pendidikan Teknik Mesin Fakultas Teknik Dan Kejuruan Universitas Pendidikan Ganesha khususnya dari angkatan ke IV (empat) Program Studi Otomotif, dimana perancangan frame dari kendaraan Ganesha Scooter Underwater tersebut pada saat ini menggunakan matrial galvanized steel.

Ganesha Scooter Underwater ini digunakan untuk kegiatan didalam air dan digerakan oleh sebuah turbin. Ganesha Scooter Underwater memiliki beberapa komponen yang terdiri dari mesin atau turbin, Frame atau rangka, dan body. Salah satu komponen yang memiliki peranan sangat penting dalam suatu kendaraan khususnya Ganesha Scooter Underwater adalah rangka atau Frame, Hal ini dikarenakan Frame pada kendaraan berfungsi sebagai penopang mesin atau turbin, serta sebagai tempat penyangga dari sistem kelistrikan sehingga menjadi satu kesatuan yang membuat scooter air dapat berjalan. Di samping sebagai penopang mesin atau turbin, Frame juga diharapkan dapat menahan beban pengendara sehingga Frame tidak mengalami kerusakaan dan selalu aman untuk dioperasikan.

Dalam perancangan Ganesha Scooter Underwater yang menggunakan material galvanized steel sebagai bahan utamanya masih di pertanyakan akan kekuatan frame, dalam Novita, 2018 galvanized steel merupakan carbon steel yang dilapisi oleh Zink (Zn) dengan komposisi senyawa adalah $\mathrm{Fe}_{3} \mathrm{C}+\mathrm{Mn}, \mathrm{S}, \mathrm{P}(\mathrm{Si})+\mathrm{Zn}$. Tujuan pelapisan dengan zink tersebut adalah sebagai pelindung agar besi maupun baja tidak terjadi korosi atau berkarat akan tetapi galvanized steel mempunyai kelemahan yaitu terjadinya korosi internal yang dimana penghalang seng hanya dapat mencegah karat untuk beberapa waktu, akan tetapi setelah lama dapat menimbulkan korosi dari dalam laut dan menyebabkan kebocoran.

Galvanized steel ini sendiri mempunyai laju korosi yang sangat cepat ketika berada dikelembaban atau berada di dalam air, dan juga korosi ini terjadi akibat sambungan (pengelasan) yang merubah sifat material dan menghilangkan kromium (pelapis anti karat) pada area sambungan tersebut sehingga galvanized steel sangat rentang terhadap air laut yang mempunyai tingkat keasaman tinggi mencapai 6.0-8.5 $\mathrm{pH}$.

Dengan adanya masalah tersebut penulis mengusulkan material baru yaitu alumunium alloys 7076-T6 (SN) yang diperuntukan dalam pembuatan frame kendaraan khususnya kendaraan didalam air, karena material alumunium alloys 7076-T6 (SN) mempunyai komposisi seng 5,6-6,1\%, magnesium 2,1-2,5\%, tembaga 1,2-1,6\% dan kurang dari setengah persen silikon, besi, mangan, titanium, kromium yang lebih tahan terhadap tingginya keasaman air laut, yang dimana material ini diterapkan pada perancangan pembuatan turbin kapal, kapal selam angkatan laut, penggunaan ruang angkasa, produksi badan pesawat, dan batrai untuk menghindari korosi dari zat asam maupun reaksi kimia lainya. Penulis juga akan 
membandingkan kekuatan frame dari material galvanized steel dengan material alumunium alloy dari rancangan frame Ganesha Scooter Underwater apakah mampu memenuhi standar menahan beban dari pengendara, yang dimana beban diasumsikan sebesar $80 \mathrm{~kg}$.

Di era kemajuan teknologi seperti sekarang ini terdapat beberapa perangkat lunak yang dapat di gunakan untuk membuat desain dari bentuk frame dan juga untuk menganalisis kekuatan dan kekokohan dari frame yang di buat. Salah satu perangkat lunak yang dapat di gunakan untuk membantu hal ini adalah software solidworks 2014.

Dari penjelasan di atas Adapun permasalahan yang akan dibahas dalam penelitian ini yaitu: dimanakah tegangan statik terbesar pada frame Ganesha Scooter Underwater menggunakan material galvanized steel dan alumunium alloys 7076-T6 (SN) dengan beban yang diasumsikan sebesar $80 \mathrm{~kg}$, Bagaimanakah perbandingan tegangan statik galvanized steel dan alumunium alloys 7076-T6 (SN) dengan beban yang diasumsikan sebesar $80 \mathrm{~kg}$.

\section{METODE}

Jenis penelitian yang digunakan pada penelitian ini adalah jenis penelitian eksperimen dengan desain one shot case study menggunakan software yang dapat mensimulasikan pengujian analisis tegangan pada rangka Ganesha Scooter Underwater dengan cara pemodelan.

Penelitian ini diawali dengan studi literatur mengenai penelitian-penelitian yang telah ada dan berbagai teori penunjang yang berkaitan dengan analisis tegangan statik pada frame kendaraan terutama pada sepeda motor. Setelah mendapatkan studi literatur yang diperlukan, dilanjutkan pada penentuan kendaraan yang akan dianalisis dalam penelitian ini. Selanjutnya dilakukan pengukuran frame dan pengumpulan data-data kendaraan yang diperlukan.

Setelah data yang diperlukan didapat, terlebih dahulu dilakukan peng- input-an material yang digunakan dalam software solidworks 2014, sebelum dilanjutkan dengan pemodelan/mendesain geometri frame awal sesuai dengan data hasil pengukuran geometri frame yang diperoleh pada software solidworks 2014. Kemudian dilanjutkan dengan melakukan analisis statik pada frame yang terbuat dari bahan material galvanized steel yang sudah dibuat dengan beban pengendara sebesar $80 \mathrm{~kg}$.

Instrumen yang digunakan dalam penelitian ini adalah observasi. Observasi dalam sebuah penelitian diartikan sebagai pemusatan perhatian terhadap objek dengan melibatkan seluruh indera untuk mendapatkan data. Sedangkan metode yang digunakan dalam penelitian ini yaitu metode elemen hingga.

\section{HASIL DAN PEMBAHASAN}

Hasil Analisis Tegangan Statik frame Material Galvanized Steel Tanpa Beban Pengendara.

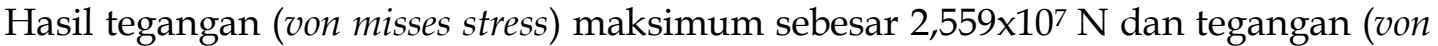
misses stress) minimum sebesar $5,234 \times 10^{3} \mathrm{~N}$ dengan input beban dari massa frame tersebut yang sebesar 178,68 N dari arah atas dan 201,105 N dari arah bawah. Berdasarkan tegangan luluh matrial galvanizeed steel yaitu $2,039 \times 10^{7} \mathrm{~N}$ bisa dipastikan jika frame tersebut tidak mampu menahan beban yang telah diberikan. Hasil dari analisis tersebut dapat dicari faktor keamanannya (factor of safety) frame tanpa beban pengendara.

$$
\begin{aligned}
& \eta=\frac{\mathrm{S}_{\mathrm{y}}}{\sigma_{\mathrm{e}}} \\
& =\frac{2,039 \times 10^{7} \mathrm{~N}}{2,559 \times 10^{7} \mathrm{~N}}=0,7967 \mathrm{~N}
\end{aligned}
$$


Hasil Analisis Tegangan Statik Frame Material Galvanized Steel dengan beban pengendara.

Hasil tegangan (von misses stress) maksimum berada pada warna merah sebesar $2,570 \times 10^{7} \mathrm{~N}$ dan tegangan (von misses stress) minimum ditampilkan dengan warna biru sebesar $5,234 \times 10^{3} \mathrm{~N}$ dengan input beban dari massa frame ditambah dengan beban pengendara yang sebesar 936,88 N dari arah atas dan 201,105 N dari arah bawah. Berdasarkan tegangan luluh

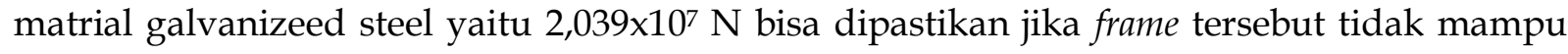
menahan beban yang telah diberikan.

Hasil dari analisis tersebut dapat dicari faktor keamanannya (factor of safety) frame dengan beban pengendara.

$$
\begin{aligned}
& \eta=\frac{\mathrm{S}_{\mathrm{y}}}{\sigma_{\mathrm{e}}} \\
& =\frac{2,039 \times 10^{7} \mathrm{~N}}{2,570 \times 10^{7} \mathrm{~N}}=0,7933 \mathrm{~N}
\end{aligned}
$$

\section{Hasil Analisis Tegangan Statik frame Material aluminium alloys 7076-T6 (SN) Tanpa Beban Pengendara.}

Hasil tegangan (von misses stress) maksimum sebesar $2,344 \times 10^{7} \mathrm{~N}$ dan tegangan (von misses stress) minimum sebesar $1,576 \times 10^{3} \mathrm{~N}$ dengan input beban dari massa frame tersebut yang sebesar 178,68 N dari arah atas dan 201,105 N dari arah bawah. Berdasarkan tegangan luluh matrial aluminum alloys 7076-T6 (SN) yaitu 5,050×108 $\mathrm{N}$ bisa dipastikan jika frame tersebut mampu menahan beban yang telah diberikan.

Hasil dari analisis tersebut dapat dicari faktor keamanannya (factor of safety) frame standar material aluminium alloys 7076-T6 (SN) tanpa beban pengendara.

$$
\begin{aligned}
\eta & =\frac{S_{\mathrm{y}}}{\sigma_{e}} \\
= & \frac{5,050 \times 10^{8} \mathrm{~N}}{2,353 \times 10^{7} \mathrm{~N}}=21,5443 \mathrm{~N}
\end{aligned}
$$

\section{Hasil Analisis Tegangan Statik frame Material aluminium alloys 7076-T6 (SN) Dengan Beban Pengendara.}

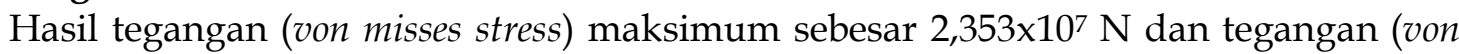
misses stress) minimum sebesar $1,639 \times 10^{3} \mathrm{~N}$ dengan input beban dari massa frame ditambah dengan beban pengendara yang sebesar 936,88 $\mathrm{N}$ dari arah atas dan 201,105 $\mathrm{N}$ dari arah bawah. Berdasarkan tegangan luluh material aluminium alloys 7076-T6 (SN) yaitu 5,050x108 bisa dipastikan jika frame tersebut mampu menahan beban yang telah diberikan.

Hasil dari analisis tersebut dapat dicari faktor keamanannya (factor of safety) frame material aluminium alloys 7076-T6 (SN) dengan beban pengendara.

$$
\begin{aligned}
\eta & =\frac{S_{y}}{\sigma_{e}} \ldots \ldots \\
& =\frac{5,050 \times 10^{8} \mathrm{~N}}{2,353 \times 10^{7} \mathrm{~N}}=21,4619 \mathrm{~N}
\end{aligned}
$$

Komparatif Tegangan Maksimum Frame Material Galvanized Steel dan Aluminium alloys 7076-T6. 


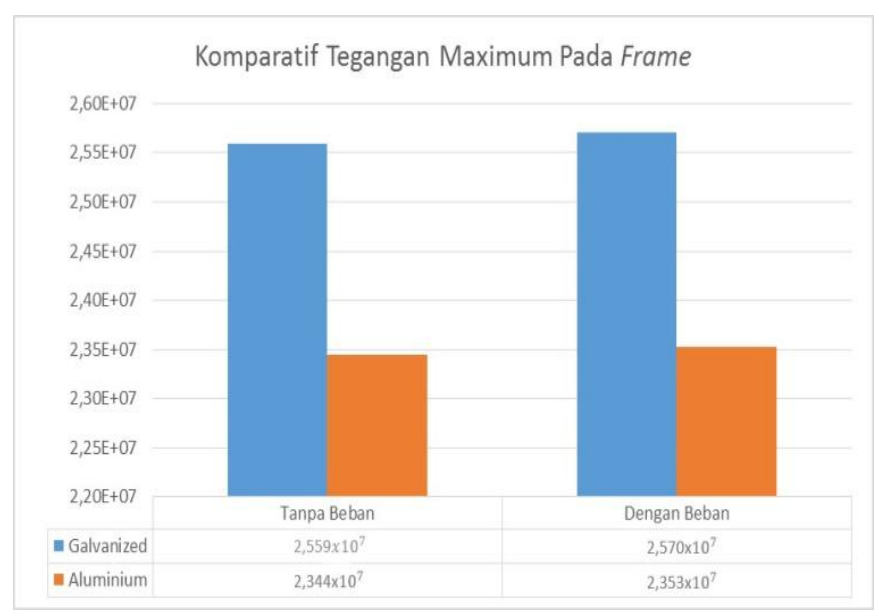

Gambar 2 Kompartif Tegangan Maksimum Pada Frame Material Galvanized Steel dan Aluminium alloys 7076-T6 (SN)

Hasil dari analisis yang telah dilakukan pada frame dengan material galvanized steel dan Aluminium alloys 7076-T6 (SN) tanpa beban pengendara maupun dengan beban pengendara. Pada grafik tersebut menunjukkan bahwa tegangan maksimum pada frame material galvanized steel tanpa beban pengendara mengalami penurunan setelah dilakukan penggantian material Aluminium alloys 7076-T6 (SN) yaitu sebesar 8,4\% dan juga tegangan maksimum pada frame dengan material galvanized steel dengan beban pengendara mengalami penurunan setelah dilakukan penggantian material Aluminium alloys 7076-T6 (SN) yaitu sebesar 8,4\%. Hal ini menunjukan bahwa semakin kecil nilai tegangan yang didapat maka kekuatan frame akan semakin baik.

\section{Komparatif Tegangan Minimum Frame Material Galvanized Steel dan Aluminium alloys} 7076-T6

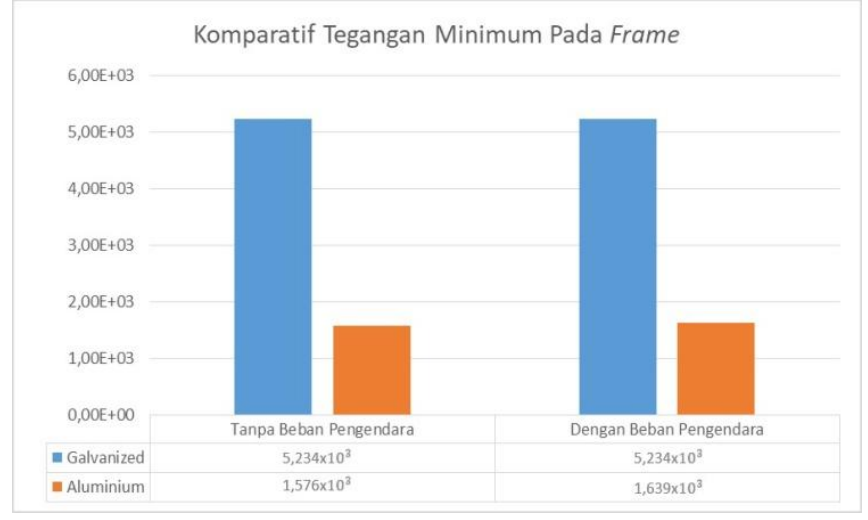

Gambar 3 Kompartif Tegangan Minimum Pada Frame Material Galvanized Steel dan Aluminium alloys 7076-T6 (SN)

Hasil dari analisis yang telah dilakukan pada frame dengan material galvanized steel dan Aluminium alloys 7076-T6 (SN) tanpa beban pengendara maupun dengan beban pengendara. Pada grafik tersebut menunjukkan bahwa tegangan minimum pada frame dengan material galvanized steel tanpa beban pengendara mengalami penurunan setelah dilakukan penggantian material Aluminium alloys 7076-T6 (SN) yaitu sebesar 69\% dan juga tegangan minimum pada frame dengan material galvanized steel dengan beban pengendara mengalami penurunan setelah dilakukan penggantian material Aluminium alloys 7076-T6 (SN) 
yaitu sebesar $68 \%$. Hal ini menunjukan bahwa semakin kecil nilai tegangan yang didapat maka kekuatan frame akan semakin.

\section{Komparatif Factor of Safety}

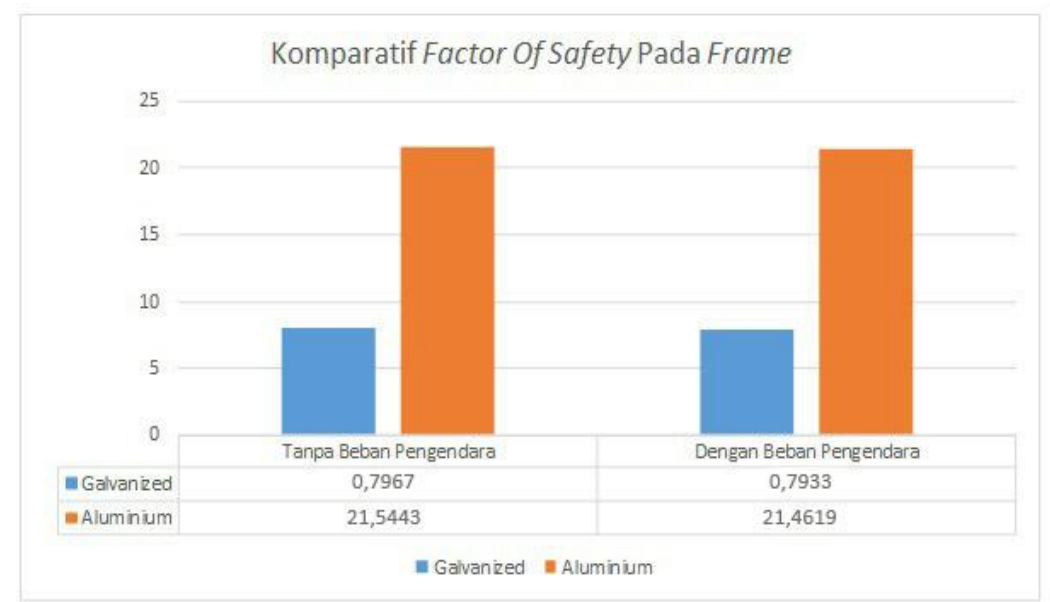

Gambar 4 Komparatif Factor of Safety Pada Frame Material Galvanized Steel dan Aluminium alloys 7076-T6 (SN)

Hasil dari analisis yang telah dilakukan pada frame material galvanized steel dan Aluminium alloys 7076-T6 (SN) tanpa beban pengendara maupun dengan beban pengendara. Pada grafik tersebut menunjukkan bahwa faktor keamanan (factor of safety) pada frame material galvanized steel tanpa beban pengendara mengalami peningkatan setelah dilakukan penggantian material Aluminium alloys 7076-T6 (SN) yaitu sebesar 63\%. Dan juga faktor keamanan (factor of safety) pada frame standar material galvanized steel dengan beban pengendara mengalami peningkatan setelah dilakukan penggantian material Aluminium alloys 7076-T6 (SN) yaitu sebesar 63,02\%. Hal ini menunjukan bahwa semakin besar faktor keamanan (factor of safety) yang didapat maka kekuatan frame juga semakin baik.

\section{KESIMPULAN DAN SARAN}

Dari hasil analisis yang telah dilakukan, didapat kesimpulan khusus yaitu frame standar yang menggunakan material aluminium alloys 7076-T6 (SN) lebih baik daripada frame standar yang menggunakan material galvaized steel,hal ini terbukti dari penurunan distribusi tegangan maksimum tanpa beban pengendara pada frame standar yang menggunakan material aluminium alloys 7076-T6 (SN) sebesar 8,4\% dan penurunan distribusi tegangan maksimum dengan beban pengendara sebesar $8,4 \%$. Selain itu penuruan distribusi tegangan minimum tanpa beban pengendara pada frame standar yang menggunakan material aluminium alloys 7076-T6 (SN) sebesar 69\% dan penurunan distribusi tegangan minimum dengan beban pengendara sebesar $68 \%$.

Semakin kecil nilai tegangan yang didapat maka kekuatan frame juga semakin baik. Peningkatan juga terjadi pada faktor keamanan (factor of safety) frame standar tanpa beban pengendara yang menggunakan material aluminium alloys 7076-T6 (SN) yaitu sebesar 32\% dan peningkatan faktor keamanan (factor of safety) frame standar dengan beban pengendara sebesar $63 \%$. Semakin besar faktor keamanan (factor of safety) yang didapat maka kekuatan frame juga semakin baik. Sehingga dapat di simpulkan bahwa frame standar yang menggunakan material aluminium alloys 7076-T6 (SN) lebih baik dan kuat dibandingkan frame standar yang menggunakan material galvaized steel. 


\section{UCAPAN TERIMA KASIH}

Penelitian ini dapat dilaksanakan dengan baik berkat bantuan beberapa pihak, untuk itu peneliti ingin mengucapkan terima kasih kepada Bapak Kadek Rihendra Dantes, S.T., M.T., selaku pembimbing I dan Bapak I Nyoman Pasek Nugraha, S.T., M.T., selaku pembimbing II .

\section{DAFTAR RUJUKAN}

Budarma, K. (2016). Analisis komparatif tegangan statik pada frame ganesha electric vehicles 1.0 generasi 1 berbasis continous variable transmission (cvt) berbantuan software ansys 14.5, [Skripsi], Jurusan Pendidikan Teknik Mesin Universitas Pendidikan Ganesha Singaraja, Indonesia.

Fadila, A. (2013). Analisis simulasi struktur chassis mobil mesin usu berbahan besi struktur terhadap beban statik dengan menggunakan perangkat lunak ansys 14.5.[skripsi], Teknik Mesin, Universitas Sumatera Utara.

Ihsan, E., Emira dkk.(2017). Aluminium. Jurnal Mahasiswa Kimia, Universitas Negeri Padang, Inodonesia. https://www.slideshare.net/nandifirdaus/jurnalaluminium diakses 18 juni 2017.

Joko, P. (2010). Aplikasi metode elemen hingga (meh) pada struktur rib bodi angkutan publik. [Skripsi], Jurusan Teknik Mesin Fakultas Teknik, Universitas Sebelas Maret.

Novita, S. (2018). Analisis laju korosi dan kekerasan pada stainless steel 304 dan baja nikel laterit dengan variasi kadar ni (0. 3. dan 10\%) dalam medium korosif. [Skripsi] Jurusan Fisika Universitas Lampung.

Setya, B. (2005). Modul chasis sepeda motor. [modul], Jurusan Pendidikan Teknik Mesin Universitas Yogyakarta (diakses 18 Juni 2018)

Saputra, I. N. A. A. (2018). Analisis tegangan statik pada rancangan frame mobil listrik ganesha sakti (gaski) menggunakan software solidworks 2014. [Skrisi], Jurusan Pendidikan Teknik Mesin Universitas Pendidikan Ganesha.

Ongga, P., Dkk. (2009). Konsepsi mahasiswa tentang tekanan hidrostatis". Universitas Yogyakarta (diakses 25 Januari 2020)

Pratama., Syahrul, B. (2016). Analisis tegangan statik pada rangka sepeda motor jenis matic menggunakan software catia p3 v5r14. [Skrisi], Teknik Mesin, Universitas Lambung Mangkurat Banjar baru.

Purwanto., Joko., Rofikoh, U. (2014). Rancang bangun perangkat eksperimen hukum archimedes. Inklusi, Jurnal Vol. 1 No.1 (diakses 25 Januari 2020)

Perdhna, Syohan, D., dkk.(2017). Studi laju korosi pada plat stainless steel (ss) dengan variasi media korosi. Jurnal Mahasiswa Jurusan Teknik Kelautan. http:/ / digilib.its.ac.id/public/ITS-Undergraduate-16971- 4307100005-paperpdf.pdf diakses (18 juni 2017). 
Sari, S. P., Santoso, P. (2014). Analisis tegangan statik pada rangka sepeda motor jenis matic menggunakan software catia 33 v5r14. [Skripsi] Program Studi Teknik Mesin, Fakultas Teknologi Industri

Wili, C., Maha. (2014). Aplikasi finite elemen analysis pada struktur rib bodi angkutan publik. [Tugas Akhir], Jurusan Teknik Mesin, Universitas Indonesia 